Topics in Current Chemistry · Vol. 146

Physical Organic Chemistry 



\section{Physical Organic Chemistry}

With 21 Figures and 27 Tables

AKADEMIE-VERLAG BERLIN 1988 
Die Originalausgabe erscheint im Springer-Verlag

Berlin · Heidelberg · New York · London · Paris · Tokyo

in der Schriftenreihe ,"Topics in Current Chemistry“,

Volume 146

Vertriebsrechte für die sozialistischen Länder:

Akademie-Verlag Berlin

Vertricbsrechte für alle Staaten mit Ausnahme der sozialistischen Länder:

Springer-Verlag Berlin · Heidelberg · New York · London · Paris · Tokyo

Alle Rechte vorbehalten

(C) Springer-Verlag Berlin · Heidelberg 1987

ISBN 3-540-18541-0 Springer-Verlag Berlin · Heidelberg · New York

ISBN 0-387-18541-0 Springer-Verlag New York · Heidelberg · Berlin

ISBN 3-05-500514-7 Akademic-Verlag Berlin

Erschienen im Akademie-Verlag Berlin, DDR-1086 Berlin, Leipziger Straße 3-4 Lizenznummer: $202 \cdot 100 / 510 / 88$

Printed in the German Democratic Republic

Gesamtherstellung: VEB Druckerei „,Thomas Müntzer“, 5820 Bad Langensalza

LSV 1275

Bestellnummer: $7638458(3072 / 146)$

14800 